\title{
Energy-efficient power regulators for electric railway vehicles
}

\author{
Leonid Astrakhantsev ${ }^{1, *}$, Natalya Ryabchyonok ${ }^{1}$, Tatyana Alekseeva ${ }^{1}$, Andrey Khomenko ${ }^{1}$, \\ and Aleksey Martusov ${ }^{1}$ \\ ${ }^{1}$ Irkutsk State Transport University, 664074 Irkutsk, Russia
}

\begin{abstract}
This study aims at validation of the power regulation parameter for electric railway vehicles for effective use of electrical potential of energy sources. Based on analysis of electromagnetic processes with the use of suggested energy parameters and mathematical modeling method the assessment of energy efficiency was performed for semiconductor power regulators for alternating and direct current electric traction drives. Power balance and obtained mathematical equations for calculation of its components allow improving the education content of educational institutions due to eliminating methodological inconsistencies. The suggested technical solutions for continuous and full use of the electrical potential of overhead systems and self-generated power supply sources ensure their advantage in terms of structure, energy efficiency and electromagnetic compatibility.
\end{abstract}

\section{Introduction}

Average energy costs of transport work amount to $12 \%$ of operating costs of the whole transportation process [1]. Global productions of power regulators for electric power consumers, which are used in all economy sectors, is characterized by the use of pulse-type utilization of the electric potential of power sources and power supply systems. Electric energy is inefficiently used to perform work in various industrial processes, emitting electromagnetic interference into the environment. This inefficiency harms both the society and the environment, hindering the development of technologies for energy-efficient use of expensive but convenient energy carriers. For the purpose of cost reduction some research are done on boosting the electric energy use by applying semiconductor devices [2-3].

The conventional technical solutions are aimed at improving the quality parameters of energy processes, however they don't eliminate the cause of unsatisfactory operation of equipment. With this aim algorithms for semiconductor converters regulation are developed based on feedbacks [4], and additional equipment is produced. Active filters and peak load compensators $[5,6]$ are used for improving electromagnetic compatibility of electric power system components. Subject of this study is energy processes in electric circuits. Specifically, the study focuses on defining and eliminating causes for decrease of their energy efficiency and increasing electromagnetic compatibility of semiconductor power regulators of electric drives for electric railway vehicles.

\footnotetext{
* Corresponding author: astrahancev1943@mail.ru
} 
Scientific substantiation of energy processes theory, which is studied in educational institutions in Russia and abroad, is based on Poynting's theorem (1885). The change in the duration of the irreversible transformation of electrical energy into another type of energy is accounted for by the conventional law of conservation of energy in the electromagnetic field [7]. However, this issue is often disregarded in the educational process, when the teachers fail to bring it to notice of their students. Power regulation in electric drives today is performed using controlled power semiconductor devices (PSD). The duration of the use of the electrical potential of energy sources for the performance of work is reduced due to current switching in PSD regulators.

The scientific problem consists in lack of mathematical dependences using which one can account the effect of PSD regulators on the duration of use of energy sources electric potential

for task performance. This study aims to develop analytical equations which account variation in the duration of use of energy sources electric potential by power regulators. The power balance at the input of a semiconductor power regulator (SPR) of the electric traction drive is suggested based on the revised energy conservation law in electromagnetic field. New energy parameters enable to eliminate methodological inconsistencies in educational process and to perform differential assessment of energy efficiency of electric power system elements. Mathematical dependences are obtained for calculating the power factor in direct current (DC) circuits. A new parameter for electric engine power control is suggested based on activating of input electrical resistance of electric traction drive.

The power factor $F_{p}$ for alternating current (AC) electric railway vehicles with a rectifier-inverter converter (RIC) and pulse phase thyristor control method can be calculated [8] using the quality attributes of the energy process $v$ and $\cos \varphi(1)$

$$
F_{P}=v \cdot \cos \varphi, v=\frac{2 \cdot \sqrt{2} \cdot \cos \frac{\alpha}{2}}{\pi \cdot \sqrt{\frac{\pi-\alpha}{\pi}}}, \cos \varphi=\cos \left(\frac{\alpha}{2}+\frac{\gamma_{1}+\gamma_{2}}{4}\right),
$$

where $v-$ is the current total harmonic distortion (THDi),

$\cos \varphi-$ is the displacement factor,

$\alpha-$ is the angle of thyristor regulation of the RIC,

$\gamma_{1}, \gamma_{2}-$ are the switching angles of RIC thyristors.

The use of formulas (1) to calculate the power factor and its dependence on $\alpha, \gamma 1, \gamma 2$ makes it possible to achieve satisfactory accuracy for engineering calculations. But the calculated dependences are applied in practice as a way to find technical solutions for increasing the current total harmonic distortion $(v \rightarrow 1)$ and for increasing the displacement factor $(\cos \varphi \rightarrow 1)$.

Frequency control of asynchronous traction motors (ATM) is performed using an autonomous inverter and pulse width modulation (PWM) at the stator windings [9, 10]. Duration of the use of the electrical potential of the power supply system shortens in the rated ATM operating conditions due to the pauses between rectangular voltage pulses (Fig.1). 


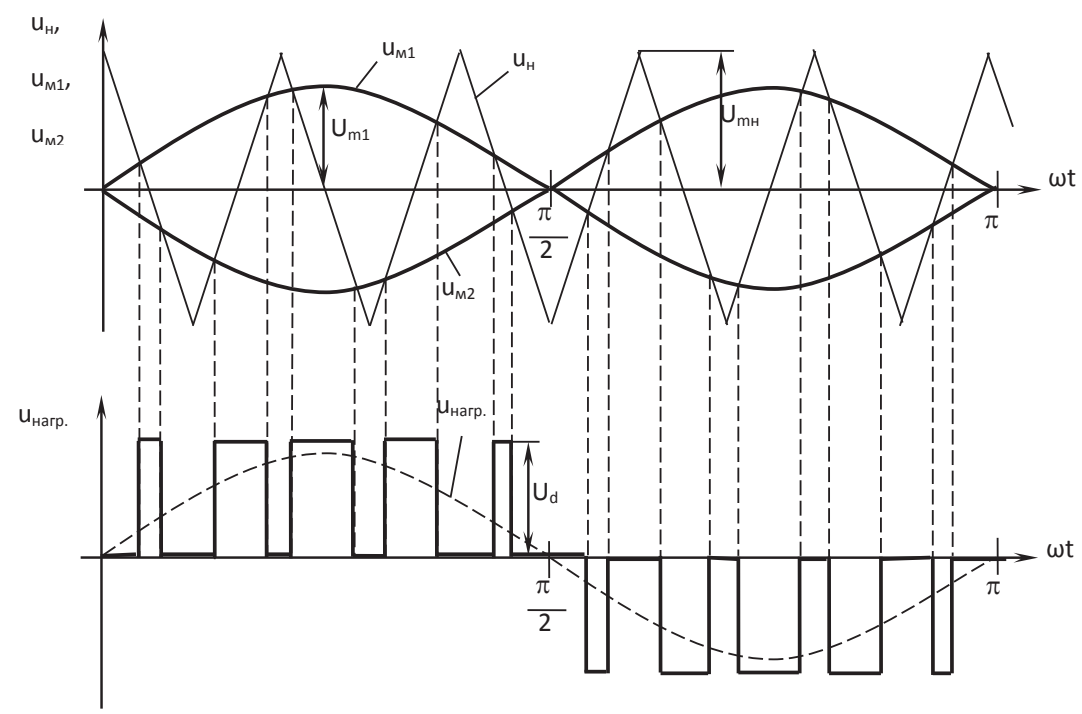

Fig. 1. Voltage timing diagrams for pulse width modulation.

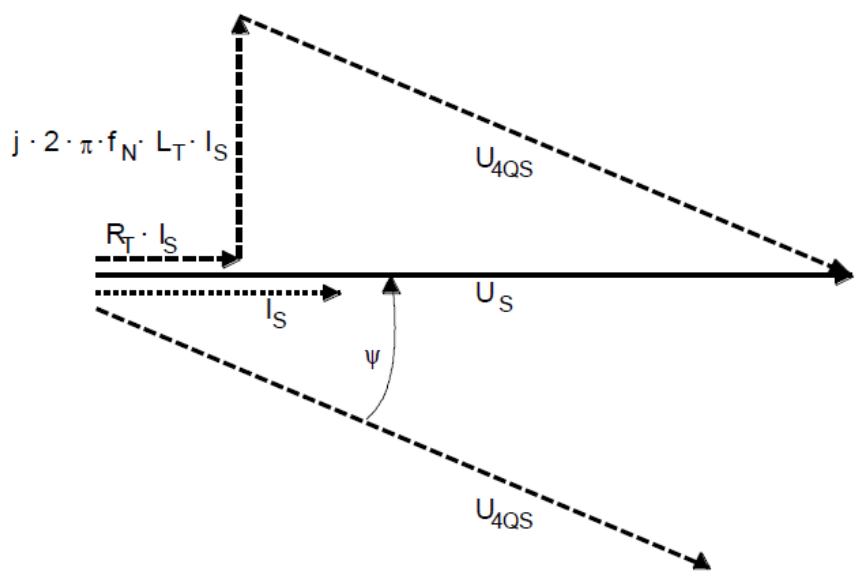

Fig. 2. Vector diagram of voltages and currents when the $4 \mathrm{qS}$ converter is operating in the rectifier mode.

ATM starting and output torque ramping are carried out with a reduced effective voltage at the stator windings and decreased frequency. To provide that the pauses between rectangular voltage pulses are increased. This approach makes it possible to reduce the duration of the irreversible transformation of electrical energy into another type of energy. PWM is used to control PSDs of four-quadrant $4 \mathrm{qS}$ converters. The pulse current envelope IS at the input of the converter $(\varphi=0)$ is matched with the instantaneous AC voltage curve $U_{S}$ in the traction mode (Fig. 2). Phase displacement occurs by the angle $\pi$ of the pulse current envelope at the converter input with the instantaneous $\mathrm{AC}$ voltage curve for the regeneration mode [11]. 


\section{Research methods}

The validation of the reason for unsatisfactory energy efficiency and electromagnetic compatibility of pulse semiconductor power regulators was carried out by refining the energy conservation law in the electromagnetic field $[12,13]$. The revised version of the law takes into account the reduction of the duration of irreversible conversion of electrical energy not only by reactive elements of the electrical circuit, but also by semiconductor devices. The power balance at the input of a semiconductor power regulator (SPR) of the electric traction drive of an electric railway vehicle (2) was obtained and new energy characteristics were

$$
\sqrt{S_{i n}^{2}-\Delta S^{2}}=\sqrt{P^{2}+Q^{2}}
$$

The total power at the regulator input $S_{\text {in }}$

$$
S_{\text {in }}=U \cdot I
$$

where U, I are the effective voltage, current at the input of the power regulator.

The component of the total power at the input of the SPR for the non-conductive state of the PSD

$$
\Delta S=\sqrt{\sum_{k=0}^{n} U_{p k}^{2} \cdot I_{k}^{2}}=U_{p} \cdot I,
$$

where $U_{P k}$ - is the effective voltage of the kth component of Fourier series at the input of the power regulator during the non-conductive state of the PSD;

$I_{k}$ - is the effective value of current of the k-th harmonic at the input of the SPR;

$U_{P}$ - is the effective voltage at the input of the SPR during the non-conductive state of the PSD;

$k-$ is the number of terms of the Fourier series, integers only;

$\mathrm{n}-$ is the number of the last harmonic counted.

Active power at the regulator input

$$
P=U_{c 0} \cdot I_{0}+\sum_{k=1}^{n} U_{c k} \cdot I_{k} \cdot \cos \varphi_{k}
$$

where $U_{c 0}, U_{c k}$ - are respectively the average voltage and the effective value of voltage of the $\mathrm{k}^{\text {th }}$ harmonic at the input of the SPR in the conductive state of the PSD;

$I_{0}, I_{k}$ - are respectively the average current and the effective value of current of the $\mathrm{k}^{\text {th }}$ harmonic at the input of the SPR.

Reactive power at the regulator input

$$
Q=\mp \sqrt{\sum_{k=1}^{n} U_{c k}^{2} \cdot I_{k}^{2} \cdot \sin ^{2} \varphi_{k}}
$$

Phase angle $\varphi_{\Sigma}$ of the total power and electrical resistance at the input of the PSD 


$$
\varphi_{\Sigma}=\operatorname{arctg}\left(\frac{\mp \sqrt{\sum_{k=1}^{n} U_{c k}^{2} \cdot I_{k}^{2} \cdot \sin ^{2} \varphi_{k}}}{U_{c 0} \cdot I_{0}+\sum_{k=1}^{n} U_{c k} \cdot I_{k} \cdot \cos \varphi_{k}}\right)
$$

The developed energy characteristics allow eliminating methodological contradictions in the process of specialist training, they also comply with the provisions of fundamental electrical engineering [14-16]. These characteristics account the influence of nonlinear distortions of voltage and current on the active and reactive power and the phase angle of the input electrical resistance (7) of the power regulator with a load. All components of the power balance (2) can be calculated and checked for the accuracy of calculation and measurement.

The power factor can be applied to estimate the energy efficiency of the use of electrical energy in direct and alternating current circuits. An assessment method is proposed for the operation of a power regulator $K_{C}$ and the effect of reactive elements of the electrical circuit $K_{Q}$ on the efficiency of the energy process (8)

$$
F_{P}=\frac{P}{S_{i n}}=\frac{\sqrt{P^{2}+Q^{2}}}{\sqrt{P^{2}+Q^{2}+\Delta S^{2}}} \cdot \frac{P}{\sqrt{P^{2}+Q^{2}}}=K_{C} \cdot K_{Q},
$$

where $K_{C}=\frac{\sqrt{P^{2}+Q^{2}}}{\sqrt{P^{2}+Q^{2}+\Delta S^{2}}}-$ is a coefficient that accounts changing by the electric railway vehicle power regulator of duration of using the electrical potential of the overhead system for train traction,

$$
K_{Q}=\frac{P}{\sqrt{P^{2}+Q^{2}}}-\text { is a coefficient that takes into account the change in the reactive }
$$
elements of the electrical circuit the duration of the irreversible conversion of electrical energy into another form of energy.

It is possible to justify the introduction of a new parameter for controlling the power of the electric traction drive of an electric railway vehicle by expressing the current at the input of the power regulator using (2) and taking into account the expressions ( $3-6)$

$$
I=\frac{\sqrt{P^{2}+Q^{2}}}{\sqrt{U^{2}-U_{P}^{2}}} .
$$

It follows from the expression (9) that in order to create an energy-efficient electric traction technology, instead of the known pulse power regulators one should use electric potential of energy sources completely and continuously $\left(U_{P}=0\right)$. A new technical solution is achieved when changing the value of input electrical resistance for power regulation and making active $\left(\varphi_{\Sigma}=0\right)$ input electric resistance of the electric traction drive. The application of the new power control parameter for electric traction drives becomes particularly relevant for mainline electric railway vehicles with a limited self-generated power supply. Regulators changing the power of the electric traction drive by controlling the input electrical resistance are discussed in detail in [17], and their effectiveness can be verified by mathematical modeling.

The mathematical model accounts the parameters of traction substation, overhead system, traction transformer of an electric railway vehicle, power regulator, traction electric drives and load. The results of calculation of the basic performance indicators of a traction 
drive were obtained using the expressions $(2-8)$, using Simulink environment and MATLAB software package.

\section{Results}

The mathematical model of operation of an electric traction drive (Fig. 3) of a DC electric railway vehicle with an input electrical resistance for regulator controlling the electric traction motor (ETM) collector with a rated voltage of $1000 \mathrm{~V}$ provides the load on the overhead system with the current $\mathrm{I}_{\mathrm{in}}=462.4 \mathrm{~A}$, and current $\mathrm{I}_{\mathrm{d}}=815.1 \mathrm{~A}$ in ETM windings.

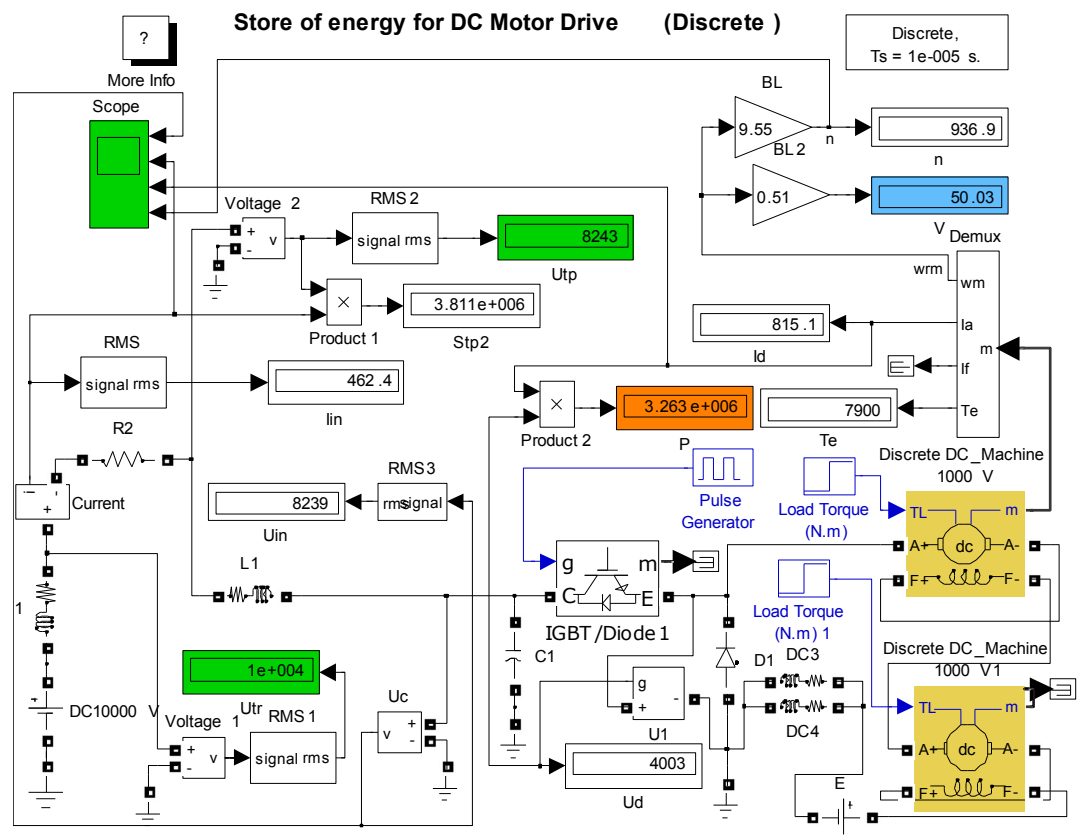

Fig. 3. Mathematical model of a DC motor drive of an electric railway vehicle with $U_{H}=10000 \mathrm{~V}$, rated traction and $\mathrm{V}=50 \mathrm{~km} / \mathrm{h}$.

This regulator can function as an electric semiconductor variator (ESV), as the total voltage on ETM windings $U_{d}=4003 \mathrm{~V}$, which is almost two times lower than the voltage on the bow current collector $U_{t p}=8243 \mathrm{~V}$ in the middle of the feeder zone of the overhead system. The power factor is $\mathrm{F}_{\mathrm{P}}=0.86$, the efficiency is $93.3 \%$. The power factor can be increased to 1 by successive enabling the electric traction motors of 2 sections of the electric railway vehicle to an intermediate storage $C_{1}$. Start, breakaway and acceleration of an electric traction drive (Fig. 4) significantly differ from those in operation of drives with conditional pulse power regulators. Once the current collector is lifted to the contact wire, the intermediate storage is charged up to the voltage $\mathrm{u}_{\mathrm{C}}=10 \mathrm{kV}$ (the first oscillogram, Fig. 4). With the voltage supplied to the windings of the electric traction motor, the current in the windings increases to $i_{d}=1000$ A (the third oscillogram, see Fig. 4) and the current is consumed in the overhead system $i_{\text {in }}$ (the second oscillogram, Fig. 4) to charge the intermediate energy storage. At the end of the acceleration, the consumed input current from the overhead system iin $=46.36 \mathrm{~A}$, and the current in ETM windings id $=802.2 \mathrm{~A}$. The moment of resistance on the shaft torque of the ETM $7772 \mathrm{~N} \cdot \mathrm{m}$ and the shaft rotation frequency $n=94 \mathrm{rpm}$ (the fourth oscillogram, Fig. 4). The power factor of a electric 
traction motor $F_{P}=0.99$ at the electric railway vehicle speed of $5 \mathrm{~km} / \mathrm{h}$, efficiency $\eta=67 \%$, mainly depending on the efficiency of the ETM in this mode of operation.

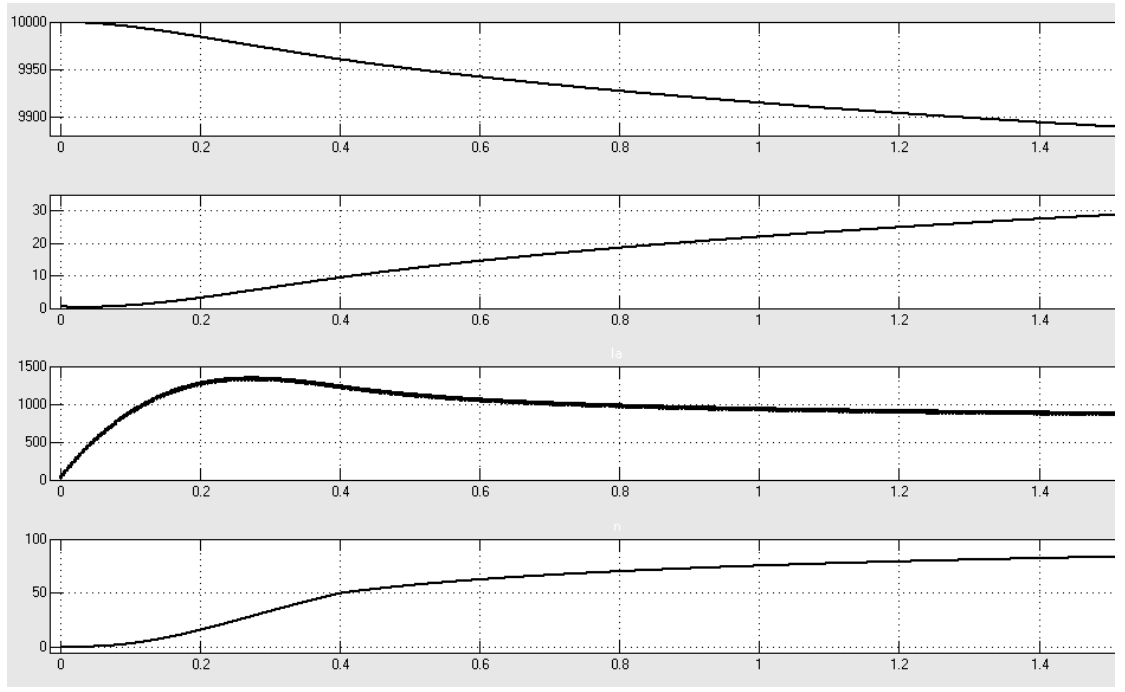

Fig. 4. Oscillograms showing the voltage $u_{C}$, input current $i_{\text {in }}$ at the input of the ESV, ETM current $I_{d}$ and the speed of rotation $n$ of the motor shaft.

A study of operation of a section of an alternating current electric railway vehicle with ATD-1200 asynchronous traction motors at the current collector voltage of $26960 \mathrm{~V}$ in the middle of the feeder zone of the overhead system of the direct current. It is made it possible to establish that at a current of 144.8 A consumed from the overhead system, the total phase current of the 4 ATMs was $1977 \mathrm{~A}$ at the vehicle movement speed of $51 \mathrm{~km} / \mathrm{h}$ and the ATM shaft drag torque of $7772 \mathrm{~N} \cdot \mathrm{m}$. The power factor of the traction drive is 0.9 , the efficiency is $90 \%$.

When starting, breaking away and accelerating, the electric traction drive of the section of the electric railway vehicles of the alternating current ESV and ATM the current consumed from the overhead system does not exceed $32 \mathrm{~A}$ in the steady state when moving at a speed of $5 \mathrm{~km} / \mathrm{h}$ and the ATM shaft drag torque of $7772 \mathrm{~N} \cdot \mathrm{m}$. The power factor is 0.91 , the power efficiency is $40.3 \%$.

\section{Conclusion}

The reason for the reduction in energy efficiency and electromagnetic compatibility of semiconductor power regulators is the reduction in the duration of irreversible conversion of electrical energy into another type of energy. The refinement of the law of conservation of energy in the electromagnetic field eliminates certain teaching problems in the educational process are eliminated. Specialists are focused on developing new engineering solutions to eliminate the cause of drawbacks of currently produced equipment. The proposed power characteristics of an electric traction drive are suitable for studies of direct and alternating current circuits with any form of instantaneous curves of voltage and current. The developed engineering solutions contribute to further development of innovative technologies in energy-efficient electric traction. 


\section{References}

1. A.T. Burkov, Elektronika i preobrazovatel'naja tehnika, [Electronics and Converter Equipment] (UMCZDT, Moscow, 2015). (in Russian)

2. M.S. Jaya Kumar, G. Ajeesh, International Journal of Electrical \& Computer Engineering, Vol. 2 (3), 339-344 (2012).

3. P.V. Prasuna, J.V.G. Rama Rao, Ch.M. Lakshmi, International Journal of Engineering Research and Applications (IJERA), Vol. 2 (4), 2368-3376 (2013).

4. K. Mohanraj, C. Lanya Bersis, S. Sekhar, Power Electronics and Renewable Energy Systems, Proceedings of ICPERES, 29-38 (2014).

5. S. Jenella, V. Radj Kumar, Power Electronics and Renewable Energy Systems, Proceedings of ICPERES, 225-236 (2014).

6. J.H. Poynting, Proceedings of the Royal Society (London, 1884).

7. O.A. Maevskiy, Energeticheskie harakteristiki ventil'nyh preobrazovatelej [Energetic characteristics of valve inverters] (Energiya, Moscow, 1978). (in Russian)

8. R.T. Shreyner, Matematicheskoe modelirovanie jelektroprivodov peremennogo toka s poluprovodnikovymi preobrazovateljami chastoty [Mathematical Simulation of Alternating Current Drives with Semiconductor Frequency] (Ural Branch of Russian Academy of Sciences, Ekaterinburg, 2000). (in Russian)

9. Yu.A. Bakhvalov, G.A. Buzalo, A.A. Zarifyan, Dinamicheskie processy v asinhronnom tjagovom privode magistral'nyh jelektrovozov [Dynamic Processes in an Asynchronous Pulling Drive of Mainline Electric Locomotives] (Marshrut, Moscow, 2006). (in Russian)

10. J. Teigelkotter, D. Sprenger, Moshhnyj preobrazovatel' na IGBT-tranzistorah dlja primenenija na zheleznodorozhnom podvizhnom sostave [Powerful converter on IGBT-transistors for use on railway rolling stock] (Siemens AG, Munich, 2000). (in Russian)

11. N.L. Ryabchyonok, T.L. Alekseeva, K.P. Yakobchuk, L.A. Astrakhantsev, Tehnicheskie Nauki. Energetika [Technical Sciencies. Power Engineering] No. 5 (2016). (in Russian)

12. T.L. Alekseeva, N.L. Ryabchyonok, L.A. Astrakhantsev, Technology of Electric Power Efficient Use in Transport, In: International Scientific Conference Energy Management of Municipal Transportation Facilities and Transport EMMFT 2017, 120-133 (2017).

13. P.A. Ionkin, Teoreticheskie osnovy elektrotehniki [Theoretical Basis of Electrical Engineering] (Vysshaja shkola, Moscow, 1976). (in Russian)

14. L.A. Bessonov, Teoreticheskie osnovy jelektrotehniki [Theoretical Basis of Electrical Engineering] (Vysshaja shkola, Moscow, 1996). (in Russian)

15. K.S. Demirchan, L.R. Neyman, N.V. Korovkin, Teoreticheskie osnovy jelektrotehniki [Theoretical Basis of Electrical Engineering] (Piter, St. Petersburg, 2009). (in Russian)

16. A.V. Vorotilkin, N.L. Mikhalchuk, N.L. Ryabchenok, T.L. Alekseeva, Science And Engineering, Vol. 13, No. 6, 62-76 (2015). (in Russian) 